\title{
Long-term results after early primary repair of tetralogy of Fallot
}

\author{
Emile A. Bacha, MDa \\ Albertus M. Scheule, MD ${ }^{\mathrm{a} *}$ \\ David Zurakowski, $\mathrm{PhD}^{\mathrm{b}}$ \\ Lars C. Erickson, MDC \\ Judy Hung, MDC \\ Peter Lang, MD ${ }^{\mathrm{C}}$ \\ John E. Mayer, Jr, MDa \\ Pedro J. del Nido, MDa \\ Richard A. Jonas, MDa
}

From the Departments of Cardiac Surgery, Biostatistics, ${ }^{\mathrm{b}}$ and Cardiology, ${ }^{\mathrm{c}}$ Children's Hospital, Harvard Medical School, Boston, Mass.

Read at the Eightieth Annual Meeting of The American Association for Thoracic Surgery, Toronto, Ontario, Canada, April 30-May 3, 2000.

Received for publication May 4, 2000; revisions requested June 20, 2000; revisions received Jan 22, 2001; accepted for publication Feb 16, 2001.

Address for reprints: Richard A. Jonas, MD, Department of Cardiac Surgery, Children's Hospital, Bader 2, 300 Longwood Ave, Boston, MA 02115. (E-mail: richard.jonas@ tch.harvard.edu).

*Evarts A. Graham Traveling Fellow, 20002001.

J Thorac Cardiovasc Surg 2001;122:154-61

Copyright (C) 2001 by The American Association for Thoracic Surgery

0022-5223/2001 $\$ 35.00+0 \quad \mathbf{1 2 / 6 / 1 1 5 1 5 6}$

doi:10.1067/mtc.2001.115156
Objective: Early primary repair of tetralogy of Fallot has been routinely performed at Children's Hospital, Boston, since 1972. We evaluated the long-term outcome of this treatment strategy including the influence of a transannular patch.

Methods: Fifty-seven patients less than 24 months of age (median 8 months) underwent primary repair of tetralogy of Fallot between January 1972 and December 1977. Thirty-one patients had a transannular patch. Survival and freedom from reintervention were determined by the Kaplan-Meier method with $95 \%$ confidence intervals.

Results: There were 8 early deaths, and 1 patient died 24 years after initial repair. Recent follow-up was obtained for 45 of the 49 long-term survivors (92\%). Median follow-up was 23.5 years. Ten patients underwent reintervention, 8 of whom underwent relief of right ventricular outflow tract obstruction. Right ventricular outflow tract obstruction occurred in 6 patients without a transannular patch and 2 with a transannular patch $(33 \%$ vs $6 \%, P=.04)$. One pulmonary valve replacement was performed at another institution 20 years after the repair. Forty-one long-term survivors were in New York Heart Association class I and 4 were in class II. Actuarial survival was $86 \%$ at 20 years (95\% confidence intervals $=80 \%-92 \%)$. Freedom from reintervention was $93 \%$ at 5 years $(95 \%$ confidence intervals $=87 \%-99 \%)$ and $79 \%$ at 20 years $(95 \%$ confidence intervals $=70 \%-86 \%)$. No significant differences were found between patients with and without a transannular patch (survival, $P=$ .34 ; freedom from reintervention, $P=.09$, log-rank tests).

Conclusions: Long-term survival is excellent and the freedom from reintervention is satisfactory after early primary repair of tetralogy of Fallot in the 1970s. Use of a transannular patch does not reduce late survival and is associated with a lower incidence of right ventricular outflow tract obstruction.

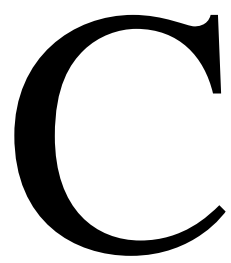

omplete repair of tetralogy of Fallot (TOF) has been performed since the 1950s. A large number of long-term studies have documented satisfactory results 30 to 40 years after reparative surgery performed at an older age and often after initial palliative surgery. ${ }^{1-4}$ The concept of early primary repair of TOF was introduced at Children's Hospital in Boston in 1972 by Castaneda and associates, ${ }^{5}$ but until now few centers have had sufficient numbers of patients operated on at an early age to allow for meaningful long-term follow-up. ${ }^{6-10}$ Controversy continues to surround the design of the surgical procedure, particularly with respect to the importance of residual pulmonary regurgitation. ${ }^{11,12}$ There is mounting concern that over the long 
TABLE 1. List of general health and cardiac questions included in the questionnaire sent to patients

General health:
General well-being
Quality of life
Sports (if any)
Exercise capacity (most recent treadmill test)
Medication
Pregnancies (attempted, complications, successful)
Cardiac:
Any heart surgery since the initial operation?
Most recent chest x-ray film
Most recent echocardiogram
Most recent cardiac catheterization
Heart rhythm problems (most recent electrocardiogram or
Holter test)

term, free pulmonary regurgitation may lead to progressive right-sided heart failure, reduced functional status, arrhythmias, reoperations, and reduced life expectancy. ${ }^{13-15}$ Some centers have reported high rates of reoperation to replace the pulmonary valve in these patients. ${ }^{12,16}$ On the other hand, residual right ventricular outflow tract (RVOT) obstruction is also known to result in a high incidence of reoperation and arrhythmias. ${ }^{11,12}$ The purpose of this study was to determine the long-term outcome after early primary repair of TOF and to assess the impact of a transannular patch (TAP).

\section{Patients and Methods \\ Patient Population}

The study population consisted of the first cohort of patients to undergo early primary repair of TOF at Children's Hospital in Boston. Between January 1972 and December 1977, 57 consecutive patients (40 boys) 24 months of age or younger underwent early primary repair of TOF and pulmonary stenosis. Median age at surgery was 8 months (range 2 weeks-24 months). Mean weight was $6.5 \pm 2.6 \mathrm{~kg}$ (range 2.0-11.4 kg). Patients with prior aortopulmonary shunts, pulmonary atresia, absent pulmonary valve, or atrioventricular septal defects were excluded from the study. Thirty-three (58\%) patients had documented cyanotic spells before the operation. Anatomic variations included a right-sided aortic arch in 9 (15\%), aortopulmonary window in 1, and an anomalous origin of the left anterior descending artery from the right coronary artery in 1 patient. Associated genetic anomalies included DiGeorge syndrome, VACTERL syndrome, ${ }^{*}$ and tracheoesophageal fistula in 1 patient each. Repair was performed with all patients under deep hypothermic circulatory arrest during this era. ${ }^{5}$ An infundibular incision was used (longitudinal in 47 patients, transverse in 10), and the ventricular septal defect was closed with interrupted sutures working through the ventriculotomy. The decision regarding use of a TAP was made after assessing the pul-

\footnotetext{
*Vertebral abnormalities, Anal atresia, Cardiac abnormalities, Tracheoesophageal fistula and/or Esophageal atresia, Renal agenesis and dysplasia, and $L$ imb defects.
}

monary valve anulus diameter. The right atrium was not opened. The pulmonary valve anulus was divided and enlarged by means of a TAP made of autologous untreated pericardium in 37 patients $(65 \%)$. The foramen ovale was deliberately left open.

\section{Study Design and Data Collection}

The design was a retrospective cohort study. All medical charts, including most recent clinic notes, echocardiography, exercise testing, and Holter reports, were reviewed. All patients not known to be dead were sent an inquiry letter. For patients who did not respond within 3 weeks, further attempts were made to locate and interview, by telephone. To locate patients who could not otherwise be found, we used a commercially based search company (US search.com, Los Angeles, Calif). Information was sought regarding the health status of each patient. Any relevant documentation with respect to recent cardiovascular events or studies was reviewed. Queries included in the questionnaire are listed in Table 1. This clinical investigation was approved by the Institutional Review Board of Children's Hospital, Boston.

\section{Statistical Analysis}

Actuarial survival and freedom from reintervention rates were determined by the Kaplan-Meier product-limit method with $95 \%$ confidence intervals (CI) derived by Greenwood's formula. Survival curves were compared by the log-rank test. ${ }^{17}$ The Cox proportionalhazards regression model ${ }^{18}$ was used to adjust for possible confounding and establish the variables independently associated with each outcome with risk measured by the hazard ratio (HR) with $95 \%$ CI. A forward stepwise selection procedure was used to derive the final multivariate equations, with the following covariates entered into the model: sex, age and weight at operation, year of operation, need for emergency surgery, presence of a genetic syndrome, coronary abnormality, and use of a TAP. Simple proportions including early mortality and the incidence of RVOT obstruction between patients with and without TAP were compared by the Fisher exact test. Biostatistical analysis was performed by means of SAS (version 6.12, SAS Institute, Cary, NC) and SPSS (version 10.0, SPSS Inc, Chicago, Ill) software packages.

\section{Results \\ Follow-up}

Cross-sectional follow-up between January 1999 and December 2000 was achieved in 31 (63\%) of the 49 long-term survivors. Median follow-up was 23.5 years (range 12 months-27 years). Thirty-eight (78\%) patients had at least 20 years of follow-up and 7 (14\%) had 10 to 20 years of followup. Four patients $(8 \%)$ were lost to follow-up within 2 years after initial repair of TOF.

\section{Survival}

Among the 57 patients, there were $8(14 \%)$ early deaths, 6 of which occurred on the operative day. Six (16\%) of the 37 patients with TAP died early compared with 2 (10\%) of the 20 patients without TAP ( $P=.69$, Fisher exact test). One late death occurred 24 years after initial repair as a result of a myocardial infarction documented at autopsy. Actuarial 
TABLE 2. Predictors of outcome

\begin{tabular}{|c|c|c|c|c|c|}
\hline \multirow[b]{2}{*}{ Outcome } & \multirow[b]{2}{*}{ Variable } & \multirow{2}{*}{$\begin{array}{c}\text { Univariable, Kaplan-Meier analysis } \\
P \text { value } \\
\end{array}$} & \multicolumn{3}{|c|}{ Multivariable, ${ }^{*}$ Cox proportional hazards analysis } \\
\hline & & & HR & $95 \% \mathrm{CI}$ & $P$ value \\
\hline \multirow[t]{8}{*}{ Overall mortality } & Sex & .1 & & & .43 \\
\hline & Age at operation (mo) & .09 & & & .94 \\
\hline & Lower weight at operation $(\mathrm{kg})$ & .007 & 2.6 & $1.2-7.7$ & .02 \\
\hline & Need for emergency surgery & .69 & & & .75 \\
\hline & Earlier year of operation & .77 & & & .8 \\
\hline & Genetic syndrome & .08 & & & .22 \\
\hline & Coronary abnormality & .71 & & & .74 \\
\hline & TAP vs non-TAP & .34 & & & .37 \\
\hline \multirow[t]{8}{*}{ Reintervention } & Sex & 61 & & & .5 \\
\hline & Age at operation (mo) & .35 & & & .79 \\
\hline & Lower weight at operation $(\mathrm{kg})$ & .49 & & & .62 \\
\hline & Need for emergency surgery & .53 & & & .74 \\
\hline & Earlier year of operation & .006 & 2.0 & $1.3-2.8$ & .01 \\
\hline & Genetic syndrome & $<.001$ & 8.3 & $2.5-35.6$ & .02 \\
\hline & Coronary abnormality & .07 & & & .13 \\
\hline & TAP vs non-TAP & & .09 & & .2 \\
\hline
\end{tabular}

$H R$, Hazard ratio; $\mathrm{Cl}$, confidence interval; TAP, transannular patch.

${ }^{*}$ Results of multivariable analysis for overall mortality (as shown) are identical to the results obtained for early mortality.

survival was $86 \%$ at 20 years $(\mathrm{CI}=80 \%-92 \%)$. There was no difference in long-term survival between the TAP and non-TAP groups (Figure $1, P=.34$, log-rank test). Table 2 presents the results of the univariable and multivariable analyses. Analysis by means of the Cox proportional hazards model revealed that lower weight at surgery was an independent risk factor for overall mortality ( $\mathrm{HR}=2.6,95 \%$ $\mathrm{CI}=1.2-7.7, P=.02)$. None of the other covariates tested were predictive of mortality (all $P>.2$ ).

\section{Reintervention}

Ten patients required a reintervention. Table 3 presents a descriptive summary of the reinterventions. The most common indication was residual or recurrent RVOT obstruction, which occurred in 8 patients. One patient who had a transannular repair was seen at another institution after 20 years with free pulmonary regurgitation, a dilated right ventricle, and fatigue. A homograft pulmonary valve replacement was performed, with slight improvement in symptoms. One patient required a defibrillator for inducible ventricular tachycardia. The patient with an anomalous anterior descending coronary artery had incomplete relief of pulmonary stenosis at the time of the primary repair. Because of the obligatory nature of his reoperation, he was excluded from subsequent statistical analysis of reinterventions. He underwent placement of a right ventricular-pulmonary artery conduit 6 years after the original procedure. Actuarial freedom from reintervention was $93 \%$ at 5 years $(95 \% \mathrm{CI}=87 \%-99 \%)$ and $79 \%$ at 20 years $(95 \% \mathrm{CI}=$ $70 \%-86 \%)$. Although the freedom from reintervention was longer for patients with a TAP than for those without a TAP, the difference did not reach statistical significance (Figure 2,
$P=.09$, log-rank test). RVOT obstruction occurred in 6 of the 18 patients with non-TAP repair compared with 2 of 31 with TAP (33\% vs $6 \%, P=.04$, Fisher exact test). Results of the multivariable analysis indicated that both earlier year of operation $(P=.01)$ and presence of a genetic syndrome $(P=.02)$ were independent risk factors for reintervention (Table 2).

To ensure that no bias was being introduced by including patients with a transverse ventriculotomy into the non-TAP group, an approach that is abandoned today, we performed a separate analysis excluding the 10 patients who had this approach. Reintervention rates were not different between the TAP and non-TAP groups $(P=.49$, log-rank test $)$, and freedom from reintervention was $100 \%(95 \% \mathrm{CI}=94 \%-100 \%)$ at 5 years and $84 \%$ at 20 years $(95 \% \mathrm{CI}=73 \%-95 \%)$.

\section{Late Functional Assessment: Exercise Tolerance, Cardiovascular Status, Medications, Reproductive Health}

Forty-one (91\%) of 45 patients having at least 10 years of follow-up (median 23 years) reported or had documented excellent exercise tolerance with no limitations to participation in sports or heavy physical activity (New York Heart Association class I). Four patients reported moderate exercise tolerance (New York Heart Association class II). One patient was receiving digoxin. Of 11 female patients with follow-up, 3 reported having uncomplicated pregnancies with a total of 5 children.

\section{Rhythm}

Thirty-four (76\%) patients had documented normal sinus rhythm according to an electrocardiogram obtained an average of $22.7 \pm 3.8$ years after the initial operation. Six 


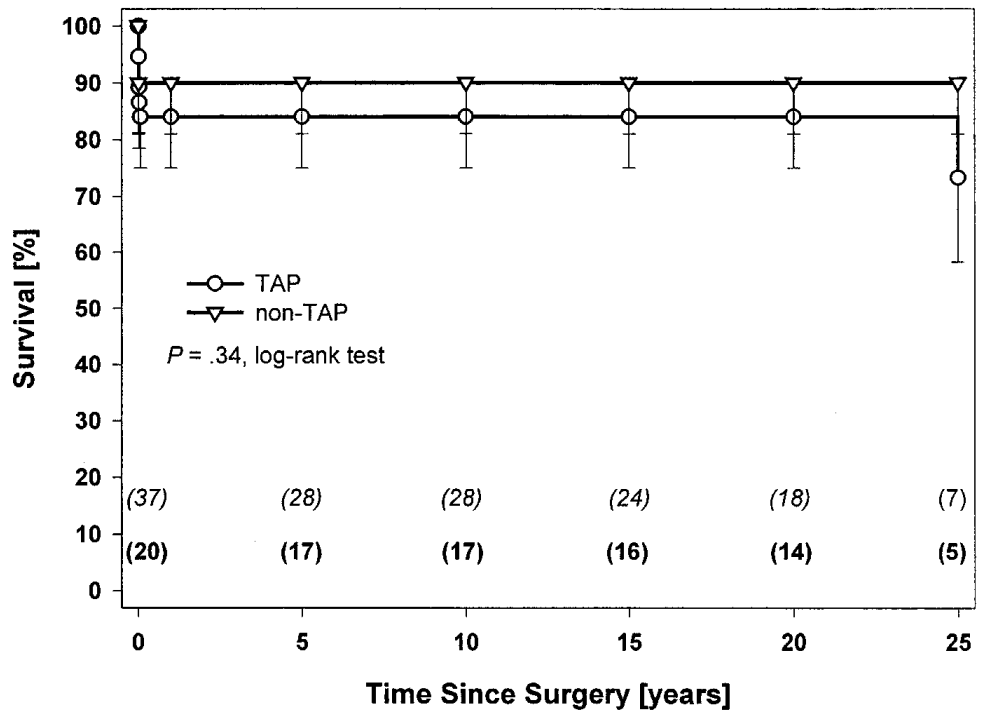

Figure 1. Kaplan-Meier estimated overall survival according to type of repair ( $P=.34$, log-rank test). Error bars denote lower $95 \%$ confidence intervals. Numbers of patients in follow-up are shown in parentheses in italics (TAP) and boldface (non-TAP).

patients had Holter monitor tests obtained 10 to 19 years after repair. One patient had inducible ventricular tachycardia and received an automatic implantable cardioverterdefibrillator; others were without notable findings.

\section{Recent Echocardiograms}

Thirty-nine (87\%) patients had an echocardiographic study performed $19.3 \pm 4.3$ years after repair. There were no residual ventricular septal defects (Figure 3).

\section{Recent Catheterizations}

Thirty-five (71\%) of the 49 long-term survivors had a cardiac catheterization study, 10 of which were performed after 1990. The indications for all of these catheter studies were echocardiographic findings of either high RVOT gradients or right ventricular dilation. Three patients needed a reintervention on the basis of the findings at catheterization.

\section{Discussion}

Current surgical management of TOF at Children's Hospital, Boston, involves early primary repair within the first 3 months of life. This approach has yielded excellent midterm results through avoidance of long-standing cyanosis, palliative shunt procedures, and right ventricular pressure overload ${ }^{19}$ but has, at least in some studies, resulted in a larger proportion of infants receiving a transannular repair. ${ }^{3,20}$ The late outcome of early repair remains uncertain, however, because most reports describe only limited follow-up. ${ }^{8-10}$ Our study substantiates the safety of transannular repair at an early age and confirms excellent long-term survival and freedom from reintervention with early primary repair.

\section{Survival}

The need for a TAP reflects the severity of the RVOT obstruction at the annular level. Consequently, patients in whom a TAP was used were at the more severe end of the morphologic spectrum. However, in this study, long-term survival of patients after transannular repair was equivalent to that of patients with anulus-sparing repairs, implying that the use of a TAP resulted in neutralization of this risk factor. Several large studies involving patients undergoing repair at an older age than in the present investigation have shown similar findings. In a series of 106 patients with 25 years of follow-up after correction of TOF, Lillehei and associates ${ }^{21}$ reported no pulmonary valve replacement or right ventricular failure. In a retrospective study with a minimum followup period of 29 years, Murphy and colleagues ${ }^{1}$ showed that the need for a TAP was not associated with reduced 30-year survival. Similarly, Meijboom and coworkers ${ }^{22}$ found no difference in long-term survival in a cohort of patients, half of whom had a TAP, 14.7 years after TOF repair. Our data extend these observations and confirm that the compensatory responses to chronic right ventricular overload can be adequate for at least 25 years. In contrast, a recent study by Nollert and colleagues ${ }^{2}$ showed that transannular repair was associated with reduced long-term survival, although these investigators found that any patch placed in the RVOT was associated with poorer long-term survival. However, many technical factors in addition to use of a TAP might influence late outcome. These factors include the length of the ventriculotomy, width of the patch, number of coronary arteries divided, preservation of the moderator band, and preservation of tricuspid valve function through careful attention to 


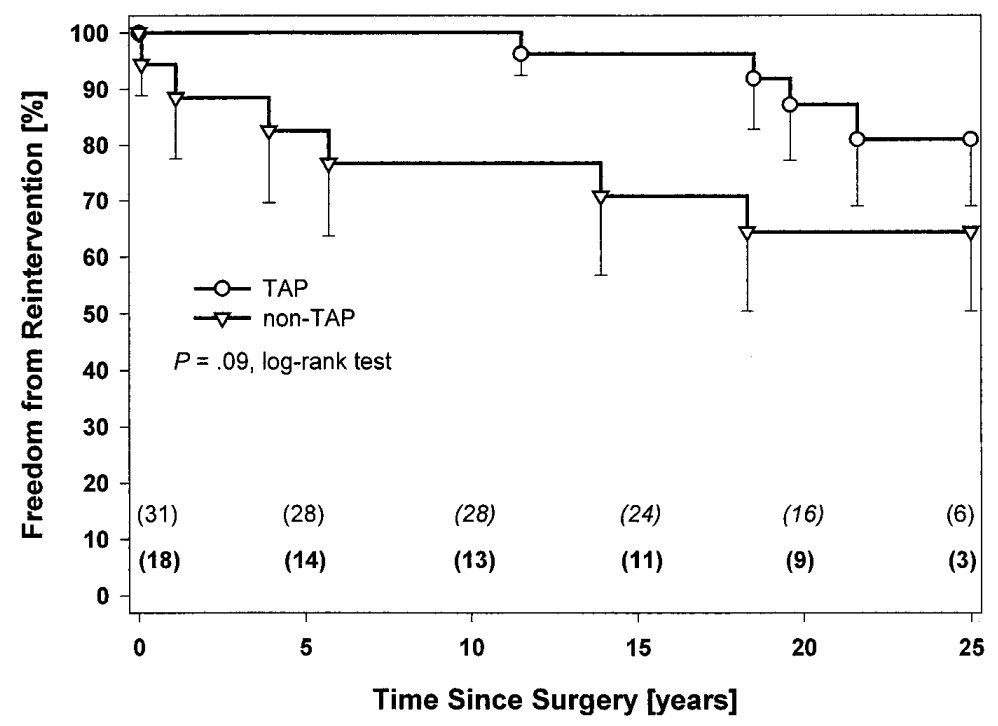

Figure 2. Kaplan-Meier estimated freedom from reintervention according to type of repair $(P=.09$, log-rank test). Error bars denote lower $95 \%$ confidence intervals. Numbers of patients in follow-up are shown parentheses in italics (TAP) and boldface (non-TAP).

TABLE 3. Clinical course of the 10 patients who had reintervention

\begin{tabular}{|c|c|c|c|c|}
\hline Patient & $\begin{array}{l}\text { Initial procedure: } \\
\text { TOF repair including: }\end{array}$ & $\begin{array}{l}\text { Indication for } \\
\text { reintervention }\end{array}$ & $\begin{array}{r}\text { Time i } \\
\text { initial operat }\end{array}$ & $\begin{array}{l}\text { interval between } \\
\text { tion and reoperation (y) }\end{array}$ \\
\hline 1 & TAP & Patch aneurysm, RVOTO & $\begin{array}{l}\text { Resection of aneurysm and } \\
\text { muscle bundles }\end{array}$ & 20 \\
\hline 2 & TAP & Dilated RV, fatigue & $\begin{array}{l}\text { Pulmonary valve replacement } \\
\text { with homograft, pacemaker }\end{array}$ & 20 \\
\hline 3 & TAP & VT & AICD & 19 \\
\hline 4 & $\begin{array}{l}\text { Primary closure of transverse } \\
\text { infundibulotomy }\end{array}$ & RVOTO, DCRV & $\begin{array}{l}\text { Resection of muscle bundles, } \\
\text { patch closure }\end{array}$ & 18 \\
\hline 5 & $\begin{array}{l}\text { Non-TAP and aortopulmonary } \\
\text { window patch repair }\end{array}$ & RVOTO & $\begin{array}{l}\text { Resection of supravalvular membrane, } \\
\text { pulmonary valvulectomy, PA plasty }\end{array}$ & 14 \\
\hline 6 & TAP & Distal main PA stenosis & PA balloon dilation & 12 \\
\hline 7 & $\begin{array}{l}\text { Non-TAP (anomalous origin } \\
\text { of LAD) }\end{array}$ & RVOTO & RV-PA conduit & 6 \\
\hline 8 & $\begin{array}{l}\text { Primary closure of transverse } \\
\text { infundibulotomy }\end{array}$ & RVOTO, residual VSD & VSD closure, patch closure & 4 \\
\hline 9 & $\begin{array}{l}\text { Patch closure of transverse } \\
\text { infundibulotomy }\end{array}$ & Patch aneurysm, RVOTO & Resection of aneurysm, TAP & 1 \\
\hline 10 & $\begin{array}{l}\text { Primary closure of transverse } \\
\text { infundibulotomy }\end{array}$ & RVOTO & TAP & 0.5 \\
\hline
\end{tabular}

TOF, Tetralogy of Fallot; TAP, transannular patch; RVOTO, right ventricular outflow tract obstruction; $R V$, right ventricle; VT, ventricular tachycardia; $A I C D$, automatic implantable cardioverter-defibrillator; $D C R V$, double-chambered right ventricle; $P A$, pulmonary artery; $L A D$, left anterior descending coronary artery.

papillary muscles, chords, and leaflets during patch placement on the ventricular septal defect. Distortion and stenosis of the pulmonary arteries, as well as elevation of pulmonary resistance by preliminary shunts, are important additional factors when a 2-stage rather than a primary repair is undertaken.

\section{Freedom From Reintervention}

Several investigators have implicated transannular patching as a risk factor for reintervention. ${ }^{12,13,16,23}$ A large body of experimental work has been published demonstrating the deleterious effects of chronic pulmonary regurgitation on right ventricular function, right ventricular volume, and 


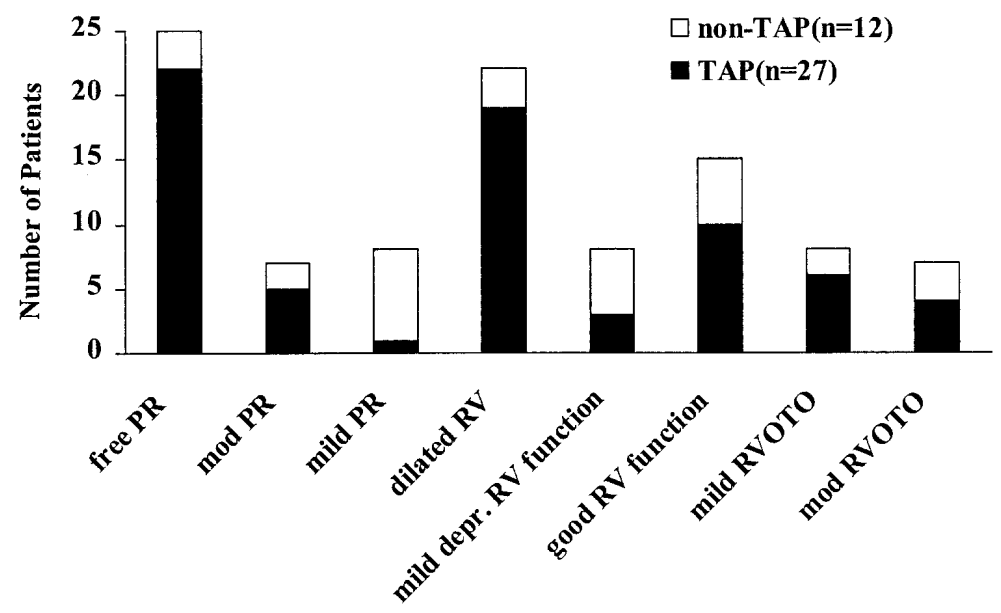

Figure 3. Late echocardiographic findings in patients after early primary repair of TOF. PR, Pulmonary regurgitation; $R V$, right ventricle; RVOTO, right ventricular outflow tract obstruction.

exercise performance. ${ }^{24,25}$ Several authors have also advocated correction of chronic pulmonary regurgitation with insertion of a valve in the RVOT, describing large series of patients undergoing this procedure. ${ }^{12,13,16,23}$ In most series, however, indications have been relatively ill-defined. Inferences are further complicated by the poor correlation between right ventricular function and exercise performance. ${ }^{24}$ In the present study, only 1 patient underwent pulmonary valve replacement, with slight improvement in symptoms.

The most common indication for reintervention in our study was residual or recurrent RVOT obstruction (8/10). This is in marked contrast to a recent study of 60 patients who underwent reoperation after previous TOF repair, in which pulmonary regurgitation was the primary indication for reoperation in 23 patients. ${ }^{23}$ A recent study of the management of TOF showed that although more patients in the first year of life had a TAP, this did not result in an increased risk for reoperation. ${ }^{3}$ Our study showed no significant difference in need for reintervention between patients with or without a TAP, although the incidence of RVOT obstruction was significantly lower in those who had a TAP. Our longstanding institutional philosophy, which is based on the evidence that residual right ventricular hypertension is a risk factor for late death, has been to eliminate aggressively important gradients across the RVOT, especially in the presence of pulmonary regurgitation. Finally, the present investigation does not show impairment in quality of life or exercise capacity, despite the presence of at least moderate pulmonary regurgitation, in patients with a TAP.

\section{Limitations of the Study}

The indications for a transannular repair versus preservation of the pulmonary valve in an infant with TOF can only be identified conclusively in a prospective randomized study. Because long-term results are excellent, a study with adequate power is unlikely to be conducted. Exercise testing was not done in our study, and the questionnaire relied, in part, on subjective data from the patient. Subtle changes in quality of life were not ascertained, and right ventricular function per se was not studied. In addition, postoperative right ventricular/left ventricular pressure ratios were not uniformly documented. Nevertheless, the long-term results after early primary repair of TOF have been satisfactory.

\section{References}

1. Murphy JG, Gersh BJ, Mair DD, Fuster V, McGoon MD, Ilstrup DM, et al. Long-term outcome in patients undergoing surgical repair of tetralogy of Fallot [see comments]. N Engl J Med. 1993;329:593-9.

2. Nollert G, Fischlein T, Bouterwek S, Bohmer C, Dewald O, Kreuzer $\mathrm{E}$, et al. Long-term results of total repair of tetralogy of Fallot in adulthood: 35 years follow-up in 104 patients corrected at the age of 18 or older. Thorac Cardiovasc Surg. 1997;45:178-81.

3. Knott-Craig CJ, Elkins RC, Lane MM, Holz J, McCue C, Ward KE. A 26-year experience with surgical management of tetralogy of Fallot: risk analysis for mortality or late reintervention. Ann Thorac Surg. 1998;66:506-11.

4. Horneffer PJ, Zahka KG, Rowe SA, Manolio TA, Gott VL, Reitz BA, et al. Long-term results of total repair of tetralogy of Fallot in childhood. Ann Thorac Surg. 1990;50:179-83.

5. Castaneda AR, Freed MD, Williams RG, Norwood WI. Repair of tetralogy of Fallot in infancy: early and late results. $J$ Thorac Cardiovasc Surg. 1977;74:372-81.

6. Mazzitelli D, Schreiber C, Guenther T, Wottke M, Meissner H, Lange R. Twenty-five years of experience with repair of tetralogy of Fallot in the first year of life [abstract]. Glasgow: European Association of Cardio-Thoracic Surgery; 1999.

7. Singh GK, Greenberg SB, Yap YS, Delany DP, Keeton BR, Monro JL. Right ventricular function and exercise performance late after primary repair of tetralogy of Fallot with the transannular patch in infancy [see comments]. Am J Cardiol. 1998;81:1378-82.

8. Hennein HA, Mosca RS, Urcelay G, Crowley DC, Bove EL. Intermediate results after complete repair of tetralogy of Fallot in neonates. J Thorac Cardiovasc Surg. 1995;109:332-44.

9. Sousa UM, Lacour-Gayet F, Komiya T, Serraf A, Bruniaux J, Touchot 
A, et al. Surgery for tetralogy of Fallot at less than six months of age. J Thorac Cardiovasc Surg. 1994;107:1291-300.

10. Reddy VM, Liddicoat JR, McElhinney DB, Brook MM, Stanger P, Hanley FL. Routine primary repair of tetralogy of Fallot in neonates and infants less than three months of age. Ann Thorac Surg. 1995;60(6 Suppl):S592-6.

11. Kirklin JW, Blackstone EH, Jonas RA, Shimazaki Y, Kirklin JK, Mayer JE Jr, et al. Morphologic and surgical determinants of outcome events after repair of tetralogy of Fallot and pulmonary stenosis: a two-institution study. J Thorac Cardiovasc Surg. 1992;103:706-23.

12. Ilbawi MN, Idriss FS, DeLeon SY, Muster AJ, Gidding SS, Berry TE, et al. Factors that exaggerate the deleterious effects of pulmonary insufficiency on the right ventricle after tetralogy repair: surgical implications. J Thorac Cardiovasc Surg. 1987;93:36-44.

13. Yemets IM, Williams WG, Webb GD, Harrison DA, McLaughlin PR, Trusler GA, et al. Pulmonary valve replacement late after repair of tetralogy of Fallot [see comments]. Ann Thorac Surg. 1997;64:526-30.

14. Norgard G, Gatzoulis MA, Moraes F, Lincoln C, Shore DF, Shinebourne EA, et al. Relationship between type of outflow tract repair and postoperative right ventricular diastolic physiology in tetralogy of Fallot: implications for long-term outcome. Circulation. 1996;94:3276-80.

15. Carvalho JS, Shinebourne EA, Busst C, Rigby ML, Redington AN. Exercise capacity after complete repair of tetralogy of Fallot: deleterious effects of residual pulmonary regurgitation. Br Heart J. 1992;67:470-3.

16. Misbach GA, Turley K, Ebert PA. Pulmonary valve replacement for regurgitation after repair of tetralogy of Fallot. Ann Thorac Surg. 1983;36:684-91.

17. Kaplan EL, Meier P. Nonparametric estimation from incomplete observations. J Am Stat Assoc. 1958;53:457-81.

18. Cox DR. Regression models and life-tables (with discussion). J R Stat Soc Series B. 1972;34:187-220.

19. Di Donato RM, Jonas RA, Lang P, Rome JJ, Mayer JE Jr, Castaneda AR. Neonatal repair of tetralogy of Fallot with and without pulmonary atresia. J Thorac Cardiovasc Surg. 1991;101:126-37.

20. Kirklin JK, Kirklin JW, Blackstone EH, Milano A, Pacifico AD. Effect of transannular patching on outcome after repair of tetralogy of Fallot. Ann Thorac Surg. 1989;48:783-91.

21. Lillehei CW, Varco RL, Cohen M, Warden HE, Gott VL, DeWall RA, et al. The first open heart corrections of tetralogy of Fallot: a 26-31 year follow-up of 106 patients. Ann Surg. 1986;204:490-502.

22. Meijboom F, Szatmari A, Deckers JW, Utens EM, Roelandt JR, Bos E, et al. Cardiac status and health-related quality of life in the long term after surgical repair of tetralogy of Fallot in infancy and childhood. $J$ Thorac Cardiovasc Surg. 1995;110:883-91.

23. Oechslin EN, Harrison DA, Harris L, Downar E, Webb GD, Siu SS, et al. Reoperation in adults with repair of tetralogy of Fallot: indications and outcomes. J Thorac Cardiovasc Surg. 1999;118:245-51.

24. Eyskens B, Reybrouck T, Bogaert J, Dymarkowsky S, Daenen W, Dumoulin M, et al. Homograft insertion for pulmonary regurgitation after repair of tetralogy of Fallot improves cardiorespiratory exercise performance. Am J Cardiol. 2000;85:221-5.

25. Jonsson H, Ivert T, Jonasson R, Holmgren A, Björk VO. Work capacity and central hemodynamics thirteen to twenty-six years after repair of tetralogy of Fallot. J Thorac Cardiovasc Surg. 1995;110:416-26.

\section{Discussion}

Dr Roger B. B. Mee (Cleveland, Ohio). Primary repair of cyanotic TOF is inherently hazardous for basic physiologic reasons. When the ventricular septal defect is closed, the right ventricle is immediately volume loaded. In addition, the right side of the heart is also insulted by suturing of the septal patch, ventriculotomy, and/or muscle resection, and it is further volume loaded from various degrees of pulmonary incompetence and sometimes tricuspid valve incompetence. Cardiopulmonary bypass and myocardial ischemia are further insults. Therefore, in repair of cyanotic TOF, the heart is being asked to do a lot more after it has been injured.
A shunt also volume loads acutely but in two well-connected ventricles in a noninsulted heart. This is all old knowledge and it cannot be changed by wishful thinking.

The median follow-up potential in this group of patients is about 26 years, and yet your median follow-up is actually only $171 / 2$ years. Furthermore, you were unable to trace 10 of the survivors. I do not think it can be assumed that the 10 survivors fared exactly the same as the ones that had some recorded follow-up.

This was an excellent opportunity to look carefully at the very concept that Boston has been promoting, namely, early primary repair of TOF. Ascribing New York Heart Association class from a questionnaire is notoriously subjective in children who have had surgery for congenital heart disease.

The manuscript's statement that early primary repair (median age 8 months) is safe is not supported by the $14 \%$ mortality $(17 \%$ for TAP) in that era, in very good hands. At exactly the same time, in Adelaide, Australia, in the hands of D'Arcy Sutherland, the annual mortality for TOF repair never exceeded 5\%. The policy of repair in those days was to operate sometime before school age in patients, some of whom had received a shunt. Therefore, I think to say that this was safe is not true. Although early primary repair is safe today, in the presence of much improved anesthesia, perfusion, myocardial protection, and postoperative care, for basic physiologic reasons it probably remains more hazardous for severely cyanotic patients than shunting followed by repair by the age of about 12 months.

What worries me with this paper is that so little information is given about the right ventricles of these patients, and that is vital information. A huge amount of temporal and objective data is missing. Potentially this is a very important group of patients because they were operated on in that era with a bold new policy, and I would like to see full, up-to-date follow-up and objective data from echocardiograms and exercise testing. You did not obtain exercise tests in any of these patients, and only about 26 had an electrocardiogram, in most cases many years ago. In terms of finding out whether the patients are alive or dead, this question was last asked somewhere between 20 and 2 years ago, in 39 of the 49 patients initially surviving the operation.

This is a most precious cohort of patients. It would be tremendously valuable to our understanding of surgery for TOF to trace all 49 initial survivors and seek up-to-date echocardiography, electrophysiology, and metabolic stress testing.

Dr Bacha. Thank you for your comments, Dr Mee.

I will first answer you question about whether it is safe to do an early repair in cyanotic newborns. I respectfully disagree with your statement regarding shunting versus complete repair. Repair in a neonate allows you to almost completely avoid resecting muscle from the infundibulum. The rate of TAP use in the neonatal age is no greater, as shown by the combined study from the University of Alabama at Birmingham and Boston in the mid-1980s. Therefore, the pathophysiology of a child who has had repair of TOF is actually more benign than that of a newborn who has received a shunt.

Regarding the patients who were lost to follow-up, obviously this is a retrospective study, and we are not pretending that it is more than that. The difficulties of identifying patients 20 years after the initial repair are widely known. However, the median follow-up remains 17.5 years and, therefore, the statistical analysis should be valid. 
The conclusion of our paper dealt with whether it is safe to use a TAP when needed. Most of the reoperations that we were able to document were done for RVOT obstruction. In trying to give our patients the best quality of life and the lowest likelihood for reoperation, each surgeon must decide whether a TAP is appropriate or not. If use of a TAP will offer the patient equal survival and a better quality of life than a repair without a TAP, with the associated risk of residual obstruction, then the TAP is the proper course.

I agree with your comments about the sophisticated right ventricular studies. We did not study right ventricular function per se. We did not use exercise testing, as has been done in other studies, and obviously those tests could be done in a future study.

Dr Francois Lacour-Gayet (Paris, France). We have similar experience at Marie-Lannelongue Hospital with the long-term results of TAP, although we have observed another cause for reoperation represented by patients with recurrent pulmonary branch stenosis.

My major comment concerns the point that you made in this paper: a right ventriculotomy is not responsible for important right ventricular dysfunction. I suspect that in your series, with operations performed early in 1972, the ventriculotomies were quite large. We are also repairing TOF through a right ventriculotomy, but this ventriculotomy is very limited.

The defenders of the right atrial approach postulate that they do no ventriculotomy. I would like to ask what the difference is between a ventriculotomy and ventriculectomy. When you resect the parietal band, you do a ventriculectomy. Therefore, the no ventriculotomy rule is questionable.

It is clear that in the youngest group of patients with TOF, who are very sick, a wider volume must be resected to create the space needed on the infundibulum. I suspect that sometimes it is necessary to go into the septum. By contrast, the ventriculotomy approach allows a minimal resection on the parietal band and sometimes no resection. Particularly in neonates, we make no incision in the parietal band in good number of patients, and we simply correct the native abnormality, that is, the anterior displacement of the septum.

My question is this: Is there associated pulmonary branch stenosis in your series?

Dr Bacha. Yes. Some pulmonary branch stenoses were seen. They were included in the RVOT obstructions. 